Case Report

\title{
Trichilemmal carcinoma associated with xeroderma pigmentosa: report of a rare case
}

\author{
Deepa R. Mane, Alka D. Kale, Seema Hallikerimath, Punnya Angadi \\ and Vijayalakshmi Kotrashetti \\ Department of Oral Pathology and Microbiology, KLE VK Institute of Dental Sciences and Hospital, \\ Belgaum, Karnataka, India
}

(Received 13 January and accepted 26 April 2010)

\begin{abstract}
Trichilemmal carcinoma is a rare malignant skin adnexal tumor derived from the outer root sheath epithelium of the hair follicle. We describe a rare case of trichilemmal carcinoma of the upper lip associated with xeroderma pigmentosa in a young patient. We demonstrate that this tumor, as well as the more frequently reported squamous cell carcinoma and basal cell carcinoma can occur in association with xeroderma pigmentosa. Making this diagnosis is imperative as the biological behavior of Trichilemmal carcinoma is less aggressive than that of other epithelial malignancies, requiring a different approach to treatment planning. (J Oral Sci 52, 505-507, 2010)
\end{abstract}

Keywords: trichilemmal carcinoma (TLC); clear cells; xeroderma pigmentosa (XP).

\section{Introduction}

Trichilemmal carcinoma (TLC) is a rare adnexal tumor related to the external hair sheath. It was first described by Headington in 1976 as a histologically invasive, cytologically atypical clear cell neoplasm of adnexal keratinocytes which is in continuity with the epidermis or follicular epithelium (1).

Clinically TLC is most often seen in older people and occurs with equal frequency in men and women. Average

Correspondence to Dr. Deepa R. Mane, Department of Oral Pathology and Microbiology, KLE VK Institute of Dental College, Nehru Nagar, Belgaum-590010, Karnataka, India

Tel: +91-9743542301

Fax: +91-8312470640

E-mail: deeparajmane@yahoo.co.in age of onset is 40 years. The pathogenesis remains unclear; however, factors like actinic damage, long-term low-dose irradiation and transformation from benign trichilemmoma have been postulated. TLC usually occurs on exposed areas of the skin, predominantly the face. It appears as a tan or flesh-colored spot - usually an isolated lesion - that can resemble a wart and sometimes contains hair. Correct diagnosis is very important because the tumor is so rare that the physician may not immediately recognize it. Generally, it is only on pathological examination that this tumor can be correctly classified (2).

We report what is, to the best of our knowledge, the first case of TLC in a young patient with xeroderma pigmentosa (XP).

\section{Case Report}

A 25-year-old man presented with a 23 years history of photophobia, vertigo, and widespread brown pigmentation. He also had a 4-year history of ulcerations on the left vermilion border of the upper lip near the corner of the mouth and on the right upper eyelid and medial canthus of the right eye. The lip lesion measured about $4 \times 2 \mathrm{~cm}$ and the eye lesion about $1 \times 1 \mathrm{~cm}$ (Fig. 1). Although the patient's parents were consanguineous, no other significant family history of similar signs and symptoms was noted. Based on the above features, a clinical provisional diagnosis of XP associated with basal cell carcinoma of the upper lip and eyelid was made. An incisional biopsy of mucosa of the left upper lip was taken and sent for histopathological examination.

\section{Histopathology}

Histologically, low magnification showed multilobular 
epithelial tumor islands interspersed with a dense fibrous connective tissue stroma (Fig. 2). At higher magnification, individual tumor aggregates showed a distinctive zonal arrangement with peripheral darkly stained squamous cells merging with centrally located clear cells. A few tumor islands showed central areas of degenerating cells forming parakeratotic debris and areas of necrosis constituting comedonecrosis. The centrally located clear cells had central nuclei with surrounding optically clear cytoplasm and prominent cell membranes. This cytoplasmic clearing was due to accumulation of glycogen, which stained positive with periodic acid Schiff stain (Fig. 3). Nuclear pleomorphism and mitotic activity was seen in both

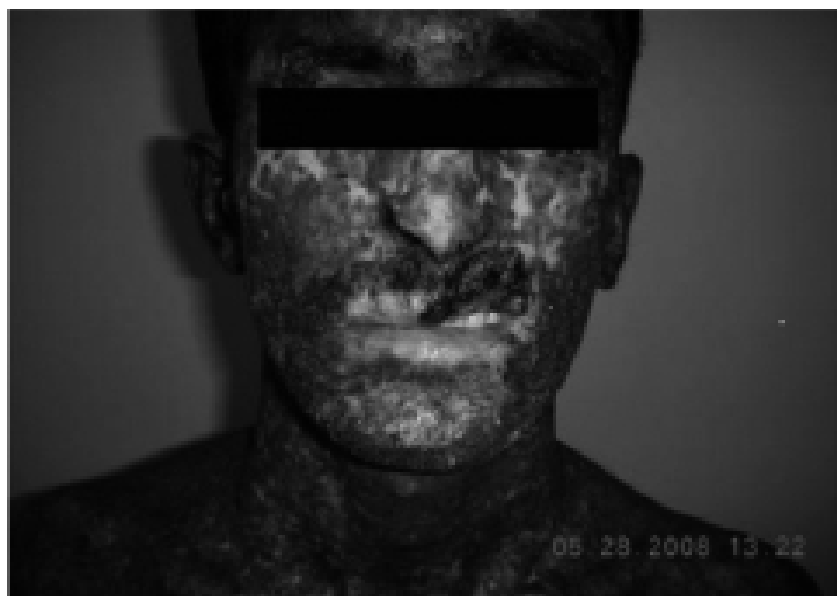

Fig. 1 Clinical photograph of the patient demonstrating xeroderma pigmentosa with ulcerations on the upper lip. He also had ulcerations of the right eyelid and medial canthus of the right eye (hidden by eyemasking).

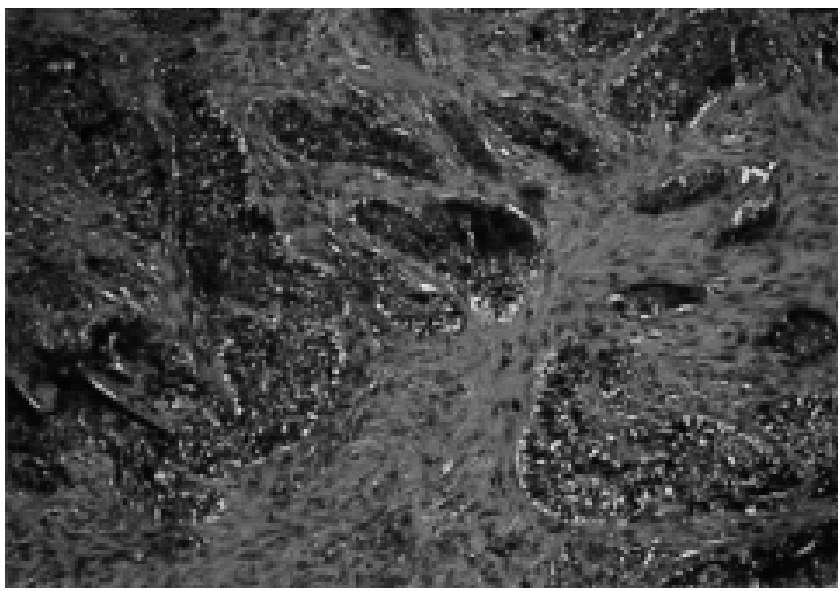

Fig. 2 Photomicrograph at low magnification showing lobulated tumor islands with peripheral hyperchromatic and central clear cells $(\mathrm{H}-\mathrm{E}$ staining $\times 10)$. cell populations. There was no evidence of keratinization. These features satisfied Headington's criteria, leading to a diagnosis of TLC (1). The patient was lost to follow up before a definitive excision could be performed.

\section{Discussion}

Skin adnexal neoplasms comprise a wide spectrum of benign and malignant tumors. They exhibit morphological differentiation toward one or more types of adnexal structures found in normal skin (3).

$\mathrm{XP}$ is a rare inherited autosomal recessive disease in which the skin cannot repair DNA damage caused by ultraviolet light. Kaposis (1800) was the first to describe this disease; it has since been reported worldwide and in all races. Affected individuals have a 2,000-fold increased risk of developing skin cancers. Basal cell carcinoma (BCC) is the most commonly associated carcinoma

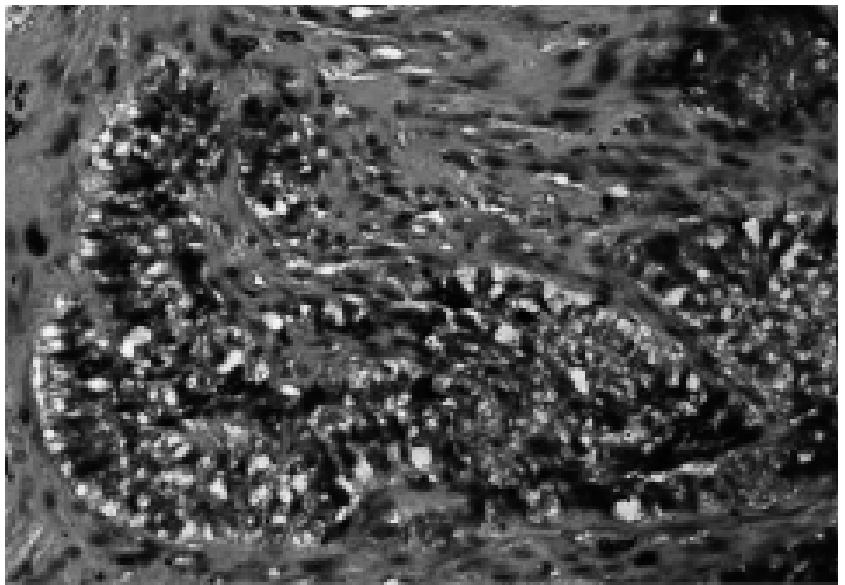

Fig. 3 Higher magnification photomicrograph showing centrally located clear cells (arrow) (H-E staining $\times 40$ ).

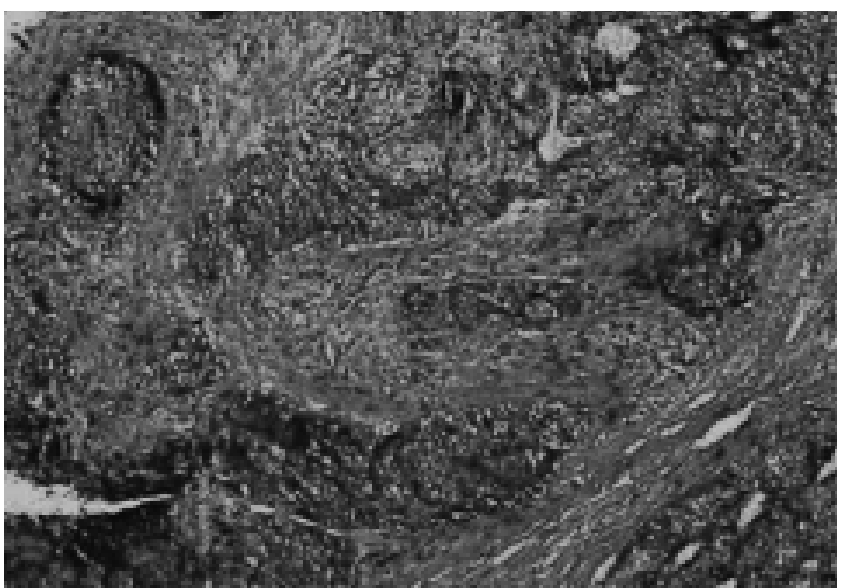

Fig. 4 Photomicrograph showing clear cells with PAS positivity $(\mathrm{PAS} \times 10)$. 
followed by squamous cell carcinoma (SCC), melanoma, and fibrosarcoma. There can be multiple basaliomas and other skin malignancies at a young age. Recurrent facial cancers and repeated surgical treatment for these in XP have important social and psychological implications that are not encountered with other cancers. The two most common causes of death in XP patients are metastatic malignant melanoma and squamous cell carcinoma (4).

Here we report a case of XP which was diagnosed only on clinical grounds due to characteristic features and was associated with TLC. This case report appears to be the first of its kind after a thorough MEDLINE and Pubmed search.

Headington first used the term TLC and originally described this neoplasm as a tumor of clear cells in continuity with a coexisting trichilemmoma. The tumor is derived from the outer root sheath epithelium of a hair follicle (5). TLC has a predictably benign course, and there are no reliable histologic criteria to predict tumor aggressiveness (6). In the present case, the lip lesion fulfilled Headington's criteria in terms of lobular arrangement, peripherally arranged hyperchromatic cells, centrally located glycogen-rich PAS-positive clear cells, and thickened basement membrane (7). Pleomorphism and mitotic activity of tumor cells was also observed.

However, TLC must be differentiated from other malignant clear cell adnexal tumors such as clear cell BCC, clear cell SCC, and sebaceous carcinoma. The areas of clear cell change in clear cell BCC often involve a minor portion of an otherwise conventional basal cell carcinoma, and some of these clear cells in this neoplasm are simply the result of degenerative changes $(8,9)$. Clear cell SCC lacks trichilemmal keratinization, lobular growth or adnexal extension. Sebaceous carcinomas demonstrate tumor lobules composed of eosinophilic cells at the periphery and absence of PAS positivity (2).

It is imperative that the correct diagnosis is made promptly as TLC has an indolent clinical course in which metastasis is rare despite the cytologically malignant appearance. Treatment includes complete surgical excision with histologically documented clear margins due to its potential for locally aggressive growth and recurrence. Since this neoplasm is easily treated with excision, there is no suggested alternative or adjunctive therapy (10).

The diagnosis of TLC, in addition to the more common basal cell carcinoma and squamous cell carcinoma, should be considered in cases of XP. This is because the prognosis is better and biological behavior more indolent for TLC than for other epithelial malignancies, leading to differences in treatment planning.

\section{References}

1. Headington JT (1976) Tumors of the hair follicle. A review. Am J Pathol 85, 479-514.

2. Lai TF, Huilgol SC, James CL, Selva D (2003) Trichilemmal carcinoma of the upper eyelid. Acta Ophthalmol Scand 81, 536-538.

3. Alsaad KO, Obaidat NA, Ghazarian D (2007) Skin adnexal neoplasms - part 1: an approach to tumours of the pilosebaceous unit. J Clin Pathol 60, 129-144.

4. Eugene DW, Joshi KD (2006) Xeroderma pigmentosa - a disfiguring disease. Kathmandu Univ Med J (KUMJ) 4, 78-81.

5. Misago N, Narisawa Y (2002) Tricholemmal carcinoma in continuity with trichoblastoma within nevus sebaceus. Am J Dermatopathol 24, 149-155

6. Swanson PE, Marrogi AJ, Williams DJ, Cherwitz DL, Wick MR (1992) Tricholemmal carcinoma: clinicopathologic study of 10 cases. J Cutan Pathol 19, 100-109.

7. Dalton SR, LeBoit PE (2008) Squamous cell carcinoma with clear cells: how often is there evidence of tricholemmal differentiation? Am J Dermatopathol 30, 333-339.

8. Wong TY, Suster S (1994) Tricholemmal carcinoma. A clinicopathologic study of 13 cases. Am J Dermatopathol 16, 463-473.

9. Barr RJ, Alpern KS, Santa Cruz DJ, Fertzin DF (1993) Clear cell basal cell carcinoma: an unusual degenerative variant. J Cutan Pathol 20, 308-316.

10. Nemetz MA, da Cunha RM, Reeck P, Neto WC, Moreira MTS, Coelho MS (2004) Trichilemmal carcinoma: a case study. Rev Bras Otorrinolaringol $70,832-835$. 